\title{
DIMENSI LIFE SKILL BERBASIS UNIFIED SPORTS SOCCER PROGRAM PADA PENDIDIKAN JASMANI TUNAGRAHITA
}

\author{
Erick Burhaein ${ }^{1}$, Sukoco ${ }^{2}$, Wisnu Satria Ghautama ${ }^{3}$ \\ ${ }^{1}$ Ikor Konsentrasi POR PPs Universitas Negeri Yogyakarta \\ ${ }^{2}$ SLB Marsudi Putra II Bantul, \\ ${ }^{3}$ SLB N 2 Yogyakarta \\ 1e-mail: erick.burhaein2016@student.uny.ac.id
}

\begin{abstract}
Abstrak
Artikel ini bertujuan untuk mengetahui pengoptimalan dimensi kecakapan hidup abad ke-21 berdasarkan program sepak bola olahraga terpadu pada pendidikan jasmani penyandang cacat intelektual. Dimensi pendidikan abad ke-21 meliputi pengetahuan, keterampilan, dan karakter yang diintegrasikan ke dalam kecakapan hidup dalam kehidupan sehari-hari. Hari ini konsep pendidikan untuk semua termasuk untuk kecacatan intelektual. Anak-anak dengan cacat intelektual, karakteristik fisiologis dan karakteristik psikologis ditandai oleh kecerdasan yang terbatas, sosial, dan fungsi mental lainnya. Dalam hal ini, perlu untuk memiliki program penanganan khusus untuk memecahkan masalah kecakapan hidup terutama dalam pendidikan jasmani untuk kecacatan intelektual. Program yang tidak pantas akan berdampak lebih kompleks pada kecakapan hidup kecacatan intelektual. Program pembentukan kecakapan hidup perlu diberikan dalam bentuk permainan olahraga, salah satunya adalah program sepakbola olahraga terpadu. Program terpadu ditandai oleh kecacatan intelektual dan kecacatan non-intelektual sebagai mitra dalam tim, dengan kecacatan intelektual tugas khusus anak sebagai pencetak gol dan pengumpan kecacatan non-intelektual. Program ini menyediakan eksplorasi diri untuk anak-anak cacat intelektual untuk meningkatkan kepercayaan diri setelah mencetak gol, dan bagi mitra untuk menghasilkan kepercayaan pada teman-teman (cacat intelektual). Berdasarkan catatan para ahli penelitian bahwa program sepak bola olahraga terpadu memiliki dampak positif pada perilaku, aktivitas pertemanan, kata sifat, termasuk faktor sosial, program adaptif, dan pengembangan individu pada kecacatan intelektual. Oleh karena itu, pembentukan kecakapan hidup berdasarkan program sepakbola olahraga terpadu cocok untuk digunakan pada kecacatan intelektual sebagai implementasi pendidikan jasmani abad ke-21.
\end{abstract}

Kata kunci: kecacatan intelektual, kecakapan hidup, program sepak bola olahraga terpadu

\begin{abstract}
This article aims to find out the optimization of 21st century life skill dimension based on unified sports soccer program on physical education of intelectual disability. The 21st century education dimension includes knowledge, skill, and character integrated into life skill in everyday life. Today the concept of education for all is included for intelectual disability. Children with intelectual disability, characteristic physiological and psychological characteristics are characterized by limited intelligence, social, and other mental functions. In this regard, it is necessary to have special handling programs to solve life skill problems especially in physical education for intelectual disability. Inappropriate programs will have a more complex impact on intelectual disability life skill. Life skill formation
\end{abstract}


program needs to be given in the form of sports game, one of them is unified sports soccer program. Unified programs are characterized by intelectual disability and non- intelectual disability activities as partners in teams, with intelectual disability child-specific tasks as goal scorers and non-intelectual disability feeders. This program provides self-exploration for intelectual disability children to boost confidence after scoring goals, and for partners to generate trust in friends (intelectual disability). Based on research experts note that unified sports soccer programs have a positive impact on behavior, friendship activity, adjective, inclusive of social factor, adaptive program, and individual development on intelectual disability. Therefore, the formation of life skill based on unified sports soccer program is suitable for use on intellectual disability as the implementation of physical education of the 21st century.

Keywords: intelectual disability, life skill, unified sports soccer program

\section{PENDAHULUAN}

Anak tunagrahita adalah anak yang memiliki hambatan pada sisi intelektual, sosial, dan emosional. Perlu adanya layanan yang tepat untuk mengoptimalkan kemampuan anak tunagrahita sehingga hambatan tersebut tidak berdampak negatif terhadap perkembangan lainnya seperti kognitif maupun psikomotor. Secara istilah Internasional, anak tunagrahita disebut intellectual and development disability (Kaufman \& Hallahan, 2011: 175). Anak tunagrahita memiliki hak yang sama dengan anak lainnya dalam pemenuhan kebutuhan, mengoptimalkan kemampuan baik dari segi layanan pendidikan maupun perkembangannya.

Layanan pendidikan, dewasa ini memiliki konsep pendidikan untuk semua termasuk bagi ATG. Anak dengan kondisi tunagrahita perlu diberikan pelayanan pendidikan yang tepat dengan analisis hambatan dan solusi pendidikan (American Psychiatric Association, 2013: 33). Ketidaktepatan pemberian layanan memberikan dampak kurang baik terhadap perkembangan ATG (Kaufman\&Hallahan, 2011: 181). Pendidikan bagi anak tunagrahita disesuaikan dengan perkembangan saat ini berbasis konsep pendidikan Abad 21.

Pendidikan di Abad 21 saat ini mengedepankan konsep penanaman life skill. Perkembangan life skill di Abad 21 terintegrasi pula di pendidikan. Dimensi pendidikan Abad 21 tidak hanya pada pengetahuan dan kemampuan saja, namun pembentukan karakter merupakan aspek penting (Bialik, et.al., 2015: 1). Berkaitan dengan hal tersebut, aktifitas pendidikan olahraga khususnya perlu 
diberikan dengan konsep sinergi antara pengetahuan, kemampuan, dan pengembangan karakter. Oleh karena itu diperlukan kesesuaian aktifitas dengan kondisi anak. Hal tersebut sesuai dengan Burhaein(2017: 57) menjelaskan bahwa aktivitas fisik perlu disesuaikan dengan pertumbuhan fisik dan perkembangan emosional.

Permainan dan olahraga bagi anak tunagrahita di awali pertama di Amerika. Di Negara tersebut dikelola oleh organisasi SOI (Special Olympic International), kemudian berkembang pesat ke seluruh dunia hingga di Indonesia melalui organisasi SOIna (Special Olympic Indonesia). Perkembangan olahraga anak tunagrahita sudah memasuki konsep life skill pendidikan Abad 21, melalui konsep unifiedsports (Rector, 2013: 1). Unifiedsportstidak hanya aktifitas untuk meningkatan pengetahuan terhadap aturan main dan keterampilan bermain olahraga tersebut, namun juga penanaman sifat dan karakter anak tunagrahita (Austin, 2013: 7).

Sport unified berkonsep inklusi bersama partner anak non-disabilitas. Ada bermacam-macam olahraga tim di Sport unified, namun permainan olahraga yang popular di dunia hingga Indonesia yaitu sepak bola atau di Amerika dikenal dengan nama soccer (Ogaora, 2013: 1). Berdasarkan hal tersebut, pembentukan life skillpendidikan Abad 21 seharusnya mampu diberikan melalui program unified sport soccer. Oleh karena itu, tujuan penulisan ini untuk mengetahui secara konseptual optimalisasi dimensi life skill abad 21 berbasisunified sports soccer program pada pendidikan jasmani anak tunagrahita.

\section{KARAKTERISTIK ANAK TUNAGRAHITA}

Karakteristik secara umum anak tunagrahita menurut Gabe (2008: 9) mengatakan ada beberapa karakteristik 1) lamban dalam mempelajari hal yang baru atau asing menurutnya, 2) akan selalu cepat lupa apa yang telah dipelajarinya, 3) dalam berbicara sangat kurang, 4) gerak dan perkembangan fisiknya sangat kurang, dan 5) kurang mampu untuk mengurus dirinya sendiri, dll.

Tunagrahita ringan (mampu didik) mempunyai karakter yang berbeda 
dengan anak normal. Menurut Mumpuniarti (2007: 41-42) menyatakan karakter anak tunagrahita ringan dapat di tinjau secara fisik, psikis dan sosial yaitu:

1. Karakter fisik nampak seperti anak normal hanya sedikit mengalami kelemahan dalam kemampuan sensomotorik.

2. Karakter psikis sukar berpikir abstrak dan logis, kurang memiliki kemampuan analisa, asosiasi lemah, fantasi lemah, kurang mampu mengendalikan perasaan, mudah di pengaruhi kepribadian, kurang harmonis karena tidak mampu menilai baik dan buruk.

3. Karakteristik sosial, mereka mampu bergaul, menyesuaikan dengan lingkungan yang tidak terbatas hanya pada keluarga saja, namun ada yang mandiri dalam masyarakat, mampu melakukan pekerjaan yang sederhana dan melakukan secara penuh sebagai orang dewasa, kemampuan dalam bidang pendidikan termasuk mampuk didik.

Senada dengan apa yang di katakan oleh Kim (2009: 220) bahwa anak tunagrahita memiliki karakteristik gerak dasar motorik yang lemah. Dari uraian pendapat para ahli di atas dapat ditarik kesimpulan bahwa anak tunagrahita ringan mempunyai karakteristik 1) mempunyai kemampuan motorik kurang, 2) kemampuan berpikir kurang, 3) dapat mencapai produktivitas tinggi dengan latihan yang di lakukan berulang- ulang, 4) kecerdasan paling tinggi setara degan anak normal usia 12 tahun.

\section{PENDIDIKAN ABAD 21}

Bialik, et.al. (2015: 1),Pusat Pengkajian Kurikulum di Boston membagi pendidikan di Abad 21 menjadi empat dimensi pendidikan: a)Knowledge, menyeimbangkan subjektifitas antara pengetahuan tradisional dan modern,b) Skill, ada korelasi sebab akibat terhadap pengetahuan, dimana skill menunjukkan tingkatan pengetahuan, c) Character berkaitan dengan perilaku dalam kehidupan. d) Metakognition sebagai bagian proses refleksi diri dan belajar dengan cara membangun ketiga aspek dimensi. 


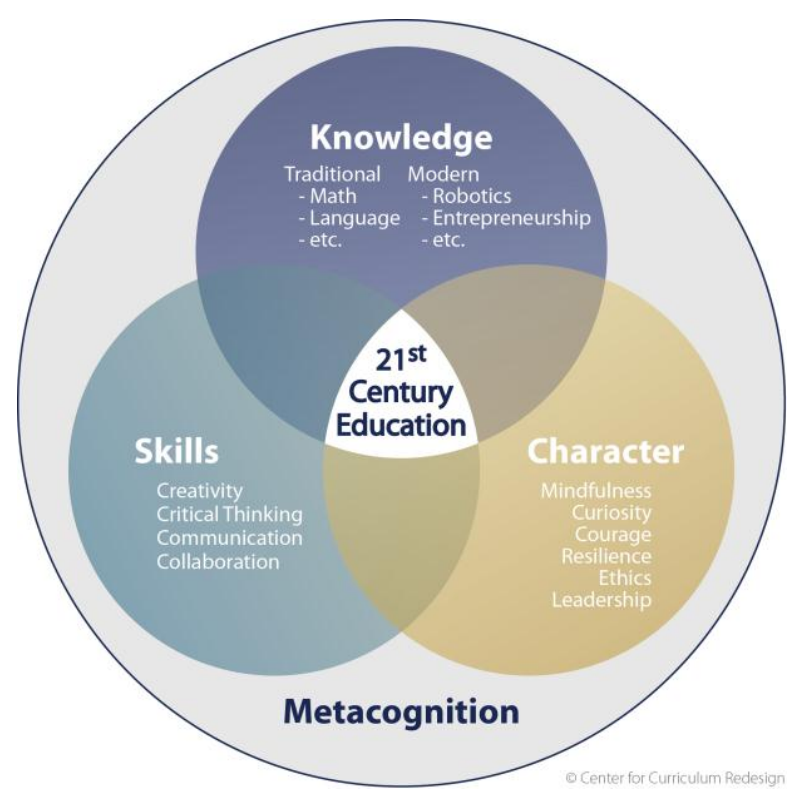

Gambar 1. Dimensi Pendidikan Abad 2 (Bialik, et.al., 2015: 1)

Salah satu dimensi di Abad 21 yaitu karakter yang di jabarkan menjadi 6 aspek. yaitu: a) Mindfulness, b) Curiosity, c) Courage, d) Resilience, e) Ethics, dan f) Leadership Lebih lanjut Bialik, dkk. (2015: 1) menjelaskan bahwa pendidikan karakter adalah tentang akuisisi dan penguatan kebajikan (kualitas), nilai (cita-cita dan konsep), dan kapasitas untuk membuat pilihan yang bijak untuk kehidupan berpengetahuan luas dan masyarakat berkembang (Bialik, et.al., 2015: $1)$.

Hal yang sama juga disampaikan Schunk (2012: 400) bahwa metakognisi mencakup sinergisitas dari tiga dimensi. Ketiga dimensi tersebut yaitu aspek pengetahuan, aspek keterampilan, dan aspek sikap. Berdasarkan kedua teori di atas dapat ditarik suatu kesimpulan bahwa di abad 21 saat ini diperlukan pengembangan metakognisi yang saling mengaitkan antardimensi pengetahuan, keterampilan, dan sikap maupun karakter. Sehingga dengan pengembangan metakognisi diharuskan mengoptimalkan keseimbangan antar dimensi tersebut.

\section{DIMENSI LIFE SKILL DI PENDIDIKAN JASMANI}

Life skill berhubungan dengan perkembangan holistik pelajar dimulai pada fase atau masa anak-anak (sedini mungkin) termasuk di lingkungan sekolah. Guru melengkapi peserta didik dengan pengetahuan, keterampilan dan nilai yang 
membantu mereka mencapai keterampilan diri dalam hidup (intelektual, potensi fisik, personal, emosional dan sosial). Subjek mendorong peserta didik untuk memperoleh dan melatih kecakapan hidup, sehingga dapat membantu mereka menjadi manusia yang aktif, mandiri, serta bertanggung jawab dalam masyarakat.

Tujuan lifeskilladalah mengajarkan keterampilan sosial yang lebih ramping. Kurikulum akan disiapkan pelajar untuk situasi kehidupan nyata.Keterlibatan dengan topik akan membantu pelajar untuk membangun nilai positif, mengubah kesalahpahaman tentang masalah kehidupan dan kehidupan dorong pelajar untuk menjalani kehidupan yang berarti.Pendidikan jasmani sendiri merupakan aktifitas yang melibatkan unsur kognitif, psikomotor, dan afektif (Burhaein, 2017: 59). Komponen tersebut merupakan standar minimum ketercapaian aktifitas jasmani di sekolah. Namun apabila dikupas lagi mengenai dimensi life skillyang terintegrasi dalam pendidikan jasmani olahraga dan kesehatan terbagi menjadi 4 domain yaitu kognitif, psikomotor, afektif, dan perilaku bugar dan sehat (Himberg,et.al., 2003: 105).

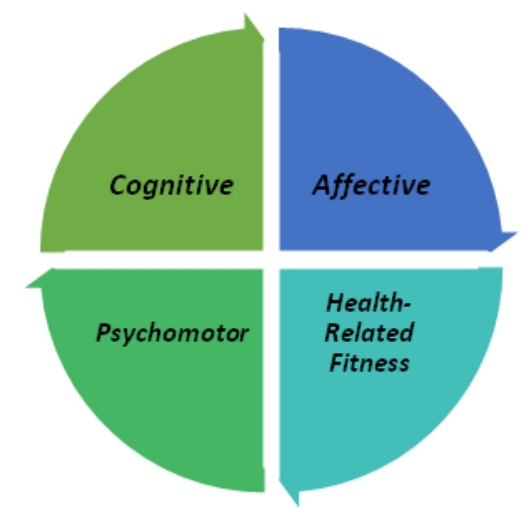

Gambar 2. Empat domain Penjas Orkes (Himberg, dkk., 2003: 105)

\section{UNIFIED SPORT SOCCER}

Rector (2013: 6) di buku panduan Special Olympic Unified Sports menjelaskan bahwa unified sports merupakan program inklusi yang mana mengkombinasikan individu disabilitas (athletes) dengan individu non-disabilitas (partners) pada olahraga bersifat tim untuk latihan maupun kompetisi. Atlet dan partner disamping melakukan pertandingan permainan olahraga, memiliki peranan 
penuh dan integral dengan tujuan unified sportsteam.

Unified sports menciptakan komposisi tim yang unik dan memberikan pengalaman baru yang tidak ditemui di olahraga lainnya. Pengalaman tersebut menciptakan sebuah kultur inklusi dan membantu perkembangan pemahaman di sekolah dan masyarakat. Tujuan unified sportsdipaparkan oleh Rector (2013: 7) diantaranya : friendships, impovisasi self esteem anak, dan perubahan positif terhadap sikap, sifat, perilaku, serta performa anak yang mengalami hambatan (permasalahan).

Jenis olahraga yang termasuk dalam Unified SportsSoccer pada dasarnya yaitu permainan yang bersifat di antaranya soccer, basketball, bocce, tennis, golf, badminton, dan bowling (Rector, 2013: 14). Berdasarkan jenis olahraga tersebut, maka soccer (istilah di USA) atau lebih dikenal istilah football (istilah international), sebagai salah satu jenis permainan favorit di dunia yang dapat dibuat dalam model inklusi.

Mengacu pada gambaran umum unified sports, maka dijelaskan pula secara spesifik tentang soccer oleh Ogaora (2013: 2) di buku panduan Unified SportsSoccer, bahwa program tersebutmenyediakan kesempatan kepada atlet dan partner untuk berlatih bersama dalam satu tim. Dimana untuk usia sekolah dasar dan menengah pertama melalui latihan tanding sepak bola, jambore, serta turnamen regional dengan acuan peraturan permainan diadaptasi dari peraturan sepak bola FIFA yang dimodifikasi sesuai tujuan dari unified sports.

\section{RANCANGAN PELAKSANAAN UNTUK UNIFIED SPORTS SOCCER PROGRAM}

Rancangan pelaksanaan Unified sports soccer Program mengacu pada petunjuk teknis baku dari SOI (Special Olympic International) di United States of America. Petunjuk teknis tersebut memuat beberapa komponen pelaksanaan program permainan di antaranya komposisi tim, perlengkapan dan lapangan pertandingan, serta peraturan permainan (Ogaora, 2013: 2-3). 
1. Komposisi Tim

a. Jumlah Pemain

Pemain terdiri dari 5 pemain inti yaitu: 3 atlet (anak tunagrahita) dan 2 partner (non-tunagrahita). Keanggotaan tim minimal 5 hingga maksimal 10 pemain setiap tim.

b. Atlet

Atlet berasal dari individu atau pemain dengan disabilitas khususnya tunagrahita. Masing-masing tim minimal memiliki 3 pemain berstatus atlet.

c. Partner

Partner berasal dari individu dengan non-disabilitas sebaiknya teman sebaya dengan usia anak tunagrahita. Masing-masing tim minimal memiliki 2 pemain.

d. Umur

Umur pemain pada jenjang usia sekolah yang sama. Atlet dan partner yang berasal dari jenjang usia sama, artinya anak usia sekolah dasar dengan usia sekolah dasar pula, usia sekolah menengah dengan usia sekolah menengah pula.

2. Perlengkapan dan Lapangan pertandingan

a. Luas area lapangan pertandingan

Luas lapangan dengan ukuran panjang 50 meter dan lebar 35 meter. Ukuran lapangan minimal yaitu panjang 40 meter dan 30 meter.

b. Goallie box size

Area kotak daerah Gawang masing-masing tim berukuran panjang 12 meter dan 8 meter.

c. Goal Size

Tiang gawang memiliki bentuk persegi panjang. Ukuran tiang gawang yang digunakan yaitu panjang 4 meter dan lebar 2 meter.

d. Ukuran bola

Ukuran bola perlu disesuaikan dengan kesetaraan fisik anak tunagrahita dengan non- tunagrahita. Penggunaan bola pada anak usia TK/ SD/ SMP menggunakan ukuran bola size 4 . 
3. Peraturan pertandingan

a. Game length

Durasi permainan ada anak usiaSD/ SMP bermain selama waktu kotor 15 menit (2x 7.5 menit), dengan istirahat half time maksimal 5 menit.

b. Start of play

Permulaan permainan, bola harus ditendang ke depan dari area titik tengah sebelum disentuh pemain lainnya. Penendang awal tidak boleh langsung menyentuh bola kembali.

c. Substitutions

Pergantian pemain, pergantian menggunakan sistem unlimited (pemain dapat kembali ke lapangan pertandingan meski telah digantikan).

d. Kick-ins

Tendangan ke dalamterjadi apabila bola telah keluar dari area line tiang gawang maka dilakukan tendangan kick-ins tanpa tendangan sudut. Tendangan dilakukan dengan kisaran jarak 5 meter dari line tiang gawang.

e. Throw-ins

Lemparan bola ke dalam, pada permainandisini tidak ada throw-ins diganti dengan kick ins pada line samping.

\section{f. Slide tackling}

Pemainunified sports soccer disini tidak diperkenankan melakukan slide tackling karena dianggap pelanggaran yang dikenai free kick pemain lawan.

g. Goalkeeper

Penjaga Gawang, seorang goal keeper bisa dari atlet ataupun partner. Penjaga gawang tidak diperbolehkan melakukan tendangan kick ins. Penjaga gawang tidak diperkenankan melakukan passing menggunakan kaki, sehingga passing bola kepada rekan tim menggunakan tangan.

h. Shooting dan Passing

Peran atlet (anak tunagrahita) haruslah dominan, dikarenakan shooting bola dilakukan atlet. Tugas seorang partner, memberi umpan terhadap atlet (anak tunagrahita). 


\section{PENGARUH UNIFIED SPORTS SOCCER PROGRAM SEBAGAI IMPLEMENTASI LIFE SKILL}

Seperti yang telah dijelaskan bahwa anak tunagrahitamemiliki karakteristik fisioligis dan psikis ditandai dengan keterbatasan intelegensi, sosial, dan fungsifungsi mental lainnya.Unified sports soccer program sebagai bentuk aktivitas permainan olahraga sepakbola mempunyai fungsi yang baik sebagai aktivitas gerak fisik serta psikologis bagi anak tunagrahita. Penggunaan Unified Soccer dirasa perlu untuk efektifitas perubahan perilaku anak tunagrahita tersebut.

Berkaitan pembentukan life skill pendidikan Abad 21, unified sports soccer dapat dijadikan sebagai program implementasi tersebut.Hal ini dibuktikan melalui penelitian-penelitian unified sport program diantaranya oleh:

1. Ozer, dkk. (2012, 229-239) menyimpulkan bahwa program unified sport soccermemberikan pengaruh positif terhadap psikososial (behaviour, friendship activity, dan adjective) anak intelectual and development disability melalui penelitian eksperimen yang dilakukan oleh timnya.

2. Bota, dkk. (2014: 21-26) menyimpulkan bahwa unified sebagai faktor sosial inklusi di komunitas sekolah untuk masyarakat usia muda dengan intelectual and development disability.

3. Alruwaih (2015: 436-441) menyimpulkan bahwa soccer unified program pada perilaku adaptif untuk anak dengan mental retardation.

4. Wilski, dkk. (2012: 271-279), menyimpulkan bahwa program olahraga pada perkembangan personal partisipan unified sport teams memberikan support positif terhadap fungsi tubuh manusia: fisik, mental, dan sosial.

Berdasarkan penelitian di atas disimpulkan bahwa unified sports khususnya cabang soccer memberi dampak positif terhadap life skill ditunjukkan dengan adanya pengaruh terhadap behaviour, friendship activity, adjective, inclusive of sosial factor, adaptif program, dan development individual anak tunagrahita. Keberhasilan program unified sports soccer mengacu pada konsep keberhasilan treatment anak tunagrahita.Valle, Kelley dan Seoanes (2001: 40) menyatakan keberhasilan terjadi melalui diagnosa dan assessment serta ketepatan treatment untuk membentuk komponen life skill pada anak tunagrahita. 


\section{SIMPULAN}

Program pembentukan life skill dapat diberikan dalam bentuk permainan olahraga, salah satunya berbasis unified sports soccer program. Program unified memiliki ciri khas yaitu aktifitas ATG dan non-ATG sebagai partner dalam tim, dengan tugas ATG sebagai pencetak gol dan non-ATG sebagai pengumpan. Program ini memberi sisi eksplorasi diri pada ATG untuk meningkatkan kepercayaan diri setelah mampu mencetak gol, serta bagi partner memunculkan rasa mempercayai teman (ATG). Sehingga dengan melalui unified sports soccer program, maka terbentuklah karakter yang positif dari masing-masing anak, baik itu anak tunagrahita maupun anak normal pada umumnya. Berdasarkan research ahli diketahui bahwa unified sports soccer program memberi dampak positif terhadap behaviour, friendship activity, adjective, inclusive of sosial factor, adaptif program, dan development individual pada ATG. Oleh karena itu, pembentukan life skill berbasis unified sports soccer program cocok digunakan pada ATG sebagai implementasi pendidikan jasmani abad 21.

\section{DAFTAR PUSTAKA}

Alruwaih, M. E. 2015. Effects of soccer unified program on adaptive behavioral for children with mental retardation. Ovidius University Annals, Physical Education and Sport/Science, Movement and Health Series, 15(2 Suppl.), 436-441.

American Psychiatric Association. 2013. Diagnostic and statistical manual of mental disorders (DSM-5). American Psychiatric Pub.

Bialik, M., Bogan, M., Fadel, C., \& Horvathova, M. 2015. Character education for the 21st century: What should students learn. Boston, Massachusetts: Center for Curriculum Redesign.

Bota, A., Teodorescu, S., \& Şerbănoiu, S. 2014. Unified Sports-a social inclusion factor in school communities for young people with intellectual disabilities. Procedia-Social and Behavioral Sciences, 117, 21-26.

Burhaein, E. 2017. Aktivitas Fisik Olahraga untuk Pertumbuhan dan Perkembangan Siswa SD. Indonesian Journal of Primary Education, 1(1), 51-58.

Burhaein, E. 2017. Aktivitas Permainan Tradisional Berbasis Neurosainslearning Sebagai Pendidikan Karakter Bagi Anak Tunalaras. Jurnal SPORTIF: Jurnal Penelitian Pembelajaran, 3(1), 55-68.

del Valle, P., Kelley, S. L., \& Seoanes, J. E. 2001. The "oppositional defiant" and "conduct disorder" child: A brief review of etiology, assessment, and treatment. Behavioral Development Bulletin, 10(1), 36. 
Gabe, R. T. 2008. Gejala Arsitektur Sekolah. Universitas Indonesia, Fakultas Teknik, Jakarta,(Skripsi).

Kauffman, J.M \& Hallahan, D.P. 2011. An Introduction: in to Exceptional Learners Special Educational. Boston: Allyn \& Bacon.

Himberg, C., Hutchinson, G., \& Roussell, J. M. 2003. Teaching secondary physical education: Preparing adolescents to be active for life. Champaign, IL: Human Kinetics.

Kim, S. Y., \& Yun, J. 2009. Determining daily physical activity levels of youth with developmental disabilities: days of monitoring required?. Adapted Physical Activity Quarterly, 26 (3), 220-235.

Mumpuniarti. 2007. Pembelajaran Akademik bagi Tunagrahita. Yogyakarta: FIP UNY.

Ogaora, C. 2013. Special Olympics Washington: Unified Soccer. SOI: United States America.

Ozer, D., Baran, F., Aktop, A., Nalbant, S., Ağlamış, E., \& Hutzler, Y. 2012. Effects of a Special Olympics Unified Sports soccer program on psychosocial attributes of youth with and without intellectual disability. Research in developmental disabilities, 33(1), 229-239.

Rector, A. 2013. Special Olympics Unified sports: A student's guide. Ed. 2. Arizona USA: Special Olympics.

Schunk, D. H. 2012. Learning theories an educational perspective sixth edition. Pearson.

Wilski, M., Nadolska, A., Dowling, S., Mcconkey, R., \& Hassan, D. 2012. Personal development of participants in Special Olympics unified sports teams. Human Movement, 13 (3), 271-279. 